\title{
Avaliação da reação varietal de cebola à antracnose foliar
}

\author{
João Américo Wordell Filho' ${ }^{1}$, Marciel João Stadnik²
}

${ }^{2}$ Epagri/ Estação Experimental de Ituporanga, Caixa Postal 121, CEP 88400-000, Ituporanga, SC. E-mail: wordell @epagri.rct-sc.br. ${ }^{2}$ Departamento de Fitotecnia, CCA, UFSC, CP 476, 88040-900 Florianópolis, SC.

Autor(a) para correspondência: João Américo Wordell Filho. wordell@ epagri.rct-sc.br

Data de chegada: 25/02/2006. Aceito para publicação em: 22/12/2008

\section{RESUMO}

Wordell Filho, J.A.; Stadnik, M.J. Avaliação da reação varietal de cebola à antracnose foliar. Summa Phytopathologica, v.34, n.3, p.284-286, 2008

A antracnose foliar (Colletotrichum gloesporioides) é uma das principais doenças na cultura da cebola no sul do Brasil, manifestandose como síndrome, conforme o estádio de desenvolvimento e variedade utilizada. Com a finalidade de melhor esclarecer esse quadro sintomatológico e selecionar variedades resistentes, avaliaram-se as reações à antracnose e sua taxa de progresso da doença em vinte e uma variedades de cebola, sob condições de casa-de-vegetação em 2004/05. As plantas foram inoculadas no estádio H (todas as folhas verdadeiras emitidas), pulverizando-se uma suspensão de $1,2 \times 10^{6}$ conídios/mL. Plantas inoculadas nunca morreram, mas apresentaram diferentes níveis de severidade. Nenhuma variedade testada revelou resistência completa ao isolado $\mathrm{Cg}$ 103. Metade das variedades, como Alfa Tropical, Alfa Tropical II, Belém IPA 9, Crioula Hortec, Crioula Roxa, Epagri 304, IPA 6, Régia, Rosada Empasc 358, Roxa IPA 3 e Super Precoce, tiveram as menores taxas de progresso da doença, sugerindo a existência de muitas fontes de resistência parcial.

Palavras chave adicionais: Allium cepa L., resistência parcial, mal-das-sete-voltas.

\section{ABSTRACT}

Wordell Filho, J.A.; Stadnik, M.J. Evaluation of varietal reaction of onion to leaf anthracnose. Summa Phytopathologica, v.34, n.3, p.284-286, 2008

Leaf anthracnose (Colletotrichum gloesporioides) is one of the most important diseases of onion in southern Brazil, manifesting as syndrome dependent upon plant growth stage and genotype. In order to better understand the symptomatological patterns and to screen resistant varieties, it was evaluated the reaction to anthracnose and the disease progress rate in 21 onion varieties under greenhouse conditions during 2004/05. Plants were inoculated at growth stage $\mathrm{H}$ (all true leaves emitted) and inoculated by spraying a suspension of
$1.2 \times 10^{6}$ conidia. Inoculated plants never died, but did show different levels of disease severity. No variety was completely resistant to the isolate $\mathrm{Cg}$ 103. However, about half of them, i.e. the varieties Alfa Tropical, Alfa Tropical II, Belém IPA 9, Crioula Hortec, Crioula Roxa, Epagri 304, IPA 6, Régia, Rosada Empasc 358, Roxa IPA 3 and Super Precoce, exhibit lower disease progress rates, suggesting the existence of several sources for partial resistance.

Additional Keywords: Allium cepa L., resistência parcial, mal-das-sete-voltas.

Antracnose-foliar da cebola (Allium cepa L.), causada por Colletotrichum gloeosporioides, tem sido relatada na maioria das regiões produtoras de cebola do Brasil, embora de ocorrência esporádica e localizada (3). É uma doença de clima sub-tropical e tropical, favorecida por freqüentes precipitações, podendo causar perdas que podem chegar a $100 \%$ na produção de bulbos, quando variedades suscetíveis são utilizadas. Na fase de armazenamento, pode causar também podridão de bulbos (6).

Em muitas regiões, tais como no Alto Vale do Itajaí, em Santa Catarina, a cebola é cultivada quase que exclusivamente no sistema de monocultivo, sem rotação de cultura e com a utilização freqüente, e muitas vezes excessiva, de fungicidas no controle da antracnose. Essa prática, além de onerar os custos de produção, pode apresentar diversas desvantagens, como a resistência do fungo a diferentes princípios ativos, intoxicação humana e contaminação ambiental. Nesse sentido, variedades com maior nível e/ou diferentes tipos de resistência, são imprescindíveis tanto para programas de melhoramento, como na busca de uma agricultura mais eficiente e ecologicamente correta. Assim, o objetivo deste trabalho foi o de avaliar a resistência de variedades de cebola à antracnose.

A pesquisa foi realizada no Laboratório de Fitopatologia e casade-vegetação da Epagri - Estação Experimental de Ituporanga, Ituporanga, SC, nos anos de 2004 e 2005. Foram avaliadas vinte e uma variedades de cebola do programa de melhoramento de cebola da Epagri e variedades comerciais, quanto à severidade e reação a $C$. gloesporioides.

A semeadura foi feita em vasos contendo aproximadamente $7 \mathrm{~kg}$ de solo, com composição média (32\% de argila; $\mathrm{pH} 5,6 ; 52$ ppm de fósforo; 202 ppm de potássio; 4,5 \% de matéria orgânica; 9,2 me/dl e $6,4 \mathrm{me} / \mathrm{dl}$ de magnésio). Foram realizadas pulverizações foliares 
Tabela 1. Escala de notas utilizadas para avaliar a reação de variedades de cebola à antracnose foliar, causada por Colletotrichum gloesporioides

\begin{tabular}{|c|c|c|}
\hline Nota & Sintomatologia & Classificação da reação \\
\hline 0 & Ausência de sintomas & Resistente (R) \\
\hline 1 & Lesões levemente deprimidas de coloração parda. & Moderadamente Resistente (MR) \\
\hline 2 & Lesões dispostas em anéis concêntricos, sem aparecimento de acérvulos. & Moderadamente Suscetível (MS) \\
\hline 3 & $\begin{array}{l}\text { Lesões dispostas em anéis concêntricos, sobre os quais desenvolvem-se acérvulos cobertos por massas de } \\
\text { conídios de coloração rosada. }\end{array}$ & Suscetível (S) \\
\hline 4 & $\begin{array}{l}\text { Plantas apresentando retorcimento e enlongamento do pseudocaule. Grande número de anéis concêntricos, } \\
\text { sobre os quais se desenvolvem acérvulos cobertos por massa de conídios de coloração rosada. }\end{array}$ & Altamente Suscetível (AS) \\
\hline
\end{tabular}

Tabela 2. Reação de resistência e agrupamento de taxas de progresso de doença em 21 variedades de cebola frente ao isolado $\mathrm{Cg} 103 \mathrm{de}$ Colletotrichum gloeosporioides sob condições de casa-de-vegetação, em 2004 e 2005.

\begin{tabular}{|c|c|c|c|c|c|}
\hline \multirow[t]{2}{*}{ Variedades } & \multirow[t]{2}{*}{ Procedência } & \multicolumn{2}{|c|}{ Ano de 2004} & \multicolumn{2}{|c|}{ Ano de 2005} \\
\hline & & $\operatorname{Reação~}^{1}$ & Grupo $^{2}$ & Rea & rupo $^{3}$ \\
\hline Alfa Tropical & Hortec & MS & 3 & $\mathrm{~S}$ & 3 \\
\hline Alfa Tropical II & Hortec & MS & 3 & S & 3 \\
\hline Belém IPA 9 & IPA & MS & 3 & S & 3 \\
\hline Conquista & Embrapa & MS & 2 & $\mathrm{~S}$ & 2 \\
\hline Crioula Hortec & Hortec & MS & 3 & $\mathrm{~S}$ & 3 \\
\hline Crioula Roxa & Epagri & MS & 3 & MS & 3 \\
\hline Diamante & Hortec & MS & 3 & $\mathrm{~S}$ & 2 \\
\hline Epagri 304 & Epagri & MS & 3 & MS & 3 \\
\hline Granex 429 & SVS & $\mathrm{S}$ & 1 & AS & 1 \\
\hline IPA 6 & IPA & MS & 3 & $\mathrm{~S}$ & 3 \\
\hline Mercedes & SVS & $\mathrm{S}$ & 1 & S & 1 \\
\hline Optima F1 & Topseed & $\mathrm{S}$ & 1 & $\mathrm{~S}$ & 1 \\
\hline Régia & SVS & $\mathrm{S}$ & 3 & S & 3 \\
\hline Rosada Empasc 58 & Epagri & MS & 3 & MS & 3 \\
\hline Roxa IPA 3 & IPA & MS & 3 & MS & 3 \\
\hline São Paulo & Embrapa & $\mathrm{S}$ & 2 & MS & 2 \\
\hline Super Precoce & Epagri & MS & 3 & $\mathrm{~S}$ & 3 \\
\hline XP 3000 & SVS & $\mathrm{S}$ & 1 & AS & 1 \\
\hline XP 3001 & SVS & $\mathrm{S}$ & 1 & AS & 2 \\
\hline XP 8010 & SVS & MS & 3 & $\mathrm{~S}$ & 2 \\
\hline Yellow Granex & - & MS & 2 & AS & 2 \\
\hline
\end{tabular}

${ }^{1} \mathrm{AR}$ : Altamente Resistente; MR: Moderadamente Resistente; MS: Moderadamente Suscetível; S: Suscetível; AS: Altamente Suscetível; avaliação aos 14 dias após inoculação.

${ }^{2}$ Grupos em $2004=1: 5,74 \pm 0,45 ; 2: 3,99 \pm 0,66 ; 3: 0,70 \pm 0,49$.

${ }^{3}$ Grupos em $2005=1: 2,97 \pm 0,36 ; 2: 1,88 \pm 0,30 ; 3: 0,92 \pm 0,34$.

semanais com um fertilizante quelatizado (Nutrifos N 10- P 50- K 10, empresa Valagro), na dosagem de $2 \mathrm{~g}$ / litro de água. A irrigação foi realizada com um regador, de acordo com as exigências hídricas da cultura. As plantas permaneceram em casa-de-vegetação durante todo o ciclo da cultura, dispostas em blocos completamente casualizados, com três repetições por tratamento. Cada repetição consistiu de um vaso contendo uma planta.

Utilizou-se o isolado monospórico Cg 103, originado de folhas com sintomas de antracnose em Ituporanga, SC. O fungo foi cultivado em placas de Petri ( $9 \mathrm{~cm}$ ), contendo o meio BDA (140 g de batata, 10 $\mathrm{g}$ de sacarose e $15 \mathrm{~g}$ de ágar por $\mathrm{L}$ de água destilada) e mantido a $2{ }^{\circ} \mathrm{C}$ com $12 \mathrm{~h}$ de fotoperíodo (Lâmpadas fluorescentes de $20 \mathrm{~W}$ emitindo 260 a 280 uEm $^{-2 . s-1}$ ). Após 10 dias de incubação, raspou-se a superfície do meio de cultura das placas e coletou-se a suspensão, que foi filtrada com duas camadas de gazes, a fim de eliminar os fragmentos de micélio. Após a calibragem da concentração com hemacitômetro (câmara de Neubauer) para $1,2 \times 10^{6}$ conídios/ mL, adicionou-se à suspensão $0,01 \%$ do surfactante Tween $80^{\circledR}$. As plantas foram inoculadas no estádio $\mathrm{H}$ (todas as folhas verdadeiras emitidas, 60 a 70 dias de idade) segundo escala de Gandin et al. (5), pulverizando-se, com auxílio de um atomizador (modelo SGA 570 DeVilbiss Co. Somerset, PA) acoplado a uma bomba de ar (pressão de $55 \mathrm{kPa}$ ), aproximadamente $20 \mathrm{~mL}$ de suspensão de conídios por planta. As plantas inoculadas foram mantidas em câmara úmida ( $98 \%$ UR, fotoperíodo de 12 h, 25 $\pm 5^{\circ} \mathrm{C}$ ) e após $48 \mathrm{~h}$, foram então transferidas para casa-de-vegetação $\left(25 \pm 5^{\circ} \mathrm{C}\right)$, onde permaneceram até a avaliação dos resultados. Durante este período, as plantas foram irrigadas a cada 3 dias utilizando-se aspersores pré-programados. As avaliações do grau de severidade foliar basearam-se na porcentagem visual de tecido necrosado, iniciadas 14 dias após a inoculação e prosseguiram regularmente em intervalos semanais, totalizando cinco avaliações, terminando no estádio I (repouso vegetativo) (5). As avaliações de reação foram realizadas 14 dias após a inoculação, baseando-se na escala de notas apresentada na Tabela 1.

Com base na severidade foliar avaliada ao longo do tempo, calculouse a taxa de progresso da doença em cada variedade, as quais foram reunidas em três grupos. O procedimento "Fastclus" do pacote estatístico SAS (1998), versão 6.12 foi usado para agrupar as variedades considerando os valores de taxa de progresso da doença.

As variedades de cebola diferiram quanto à reação de resistência $\mathrm{e}$ à taxa de progresso da doença à antracnose, causada por $C$. gloesporioides (Tabela 2). Diferenças nas reações das variedades de cebola frente a diferentes isolados de C. gloesporioides tem sido frequentemente relatadas em outros trabalhos $(1,2,4,10)$. Neste trabalho, a resistência manifestada nas variedades de cebola foi intermediária, pois nenhum material apresentou altos níveis de resistência ou imunidade.

Quanto à reação à antracnose, todas as variedades apresentaram diferentes níveis de suscetibilidade. Nos dois anos de avaliação em casa-de-vegetação, as variedades Roxa IPA 3, Crioula Roxa, Epagri 304 e Rosada-Empasc 358 foram consideradas moderadamente suscetíveis, enquanto as variedades XP 3000, XP 3001, Granex 429, Régia, Mercedes e Optima F1 foram suscetíveis.

De fato, poucas fontes consistentes de resistência em Allium cepa são atualmente disponíveis e ainda há um quase total desconhecimento tanto da herança genética, como do provável complexo de patótipos existentes. Galván et al. (4) encontraram, por exemplo, um alto nível de resistência a um isolado proveniente de Santa Catarina somente em 
acessos de espécies selvagens do gênero Allium, que foram no entanto, suscetíveis a isolados da Nigéria e Indonésia. A resistência apresentada por Allium roylei ao isolado brasileiro é herdada de maneira dominante e provavelmente governada por mais que um gene, havendo a possibilidade de usar esta espécie em programas de melhoramento da cebola.

Por outro lado, outros autores $(1,10)$, avaliando o índice de sobrevivência de plântulas, observaram reação de imunidade em três variedades de A. porrum e resistência nas variedades Barreiro, Roxa Chata e Branca Chata. Mas não se relatou se as plantas sobreviventes ficaram doentes e em que grau de severidade. No presente trabalho não houve morte de plantas, mesmo quando severamente infectadas por $C$. gloeosporioides. Nos estudos de Silva \& Costa (10) onde se avaliou a reação de variedades e híbridos de cebola à antracnose, plântulas foram inoculadas mais cedo ou mesmo, imediatamente após a emergência, ocasionando morte delas em variedades suscetíveis. É possível que outros genes de resistência se expressem de maneira diferenciada em diferentes estádios fenológicos e por este motivo, extrapolações diretas entre os resultados desses trabalhos ficam prejudicadas, senão impossibilitadas. Na verdade, níveis variáveis na taxa de sobrevivência de variedades de cebola a $C$. gloeosporioides têm sido observados e relacionados com herança poligênica e aditiva $(8,10)$.

Sabe-se que $C$. gloeosporioides pode causar tombamento quando veiculado pela semente $(3,8)$. A infecção nos primeiros meses pode também induzir o retorcimento foliar, deixando o pescoço mais endurecido e de cor verde-clara, conhecido como "mal-das-sete-voltas". Caso a infecção ocorra mais tarde, como neste trabalho, pode haver redução da parte aérea e emissão de novas raízes, fazendo com que haja o rompimento das escamas dos bulbos próximo à coroa e tornandoos mais frágeis no armazenamento (3). Nas condições de Santa Catarina, a infecção tardia é, aliás, o principal problema associado à antracnose foliar, não havendo problemas relatados em fase de canteiro, devido principalmente às condições de temperatura amenas abaixo de $20^{\circ} \mathrm{C}$ que restringe a ocorrência da doença nesse estádio. Por este motivo é importante selecionar variedades com resistência na fase adulta e de pós-colheita.

A análise de agrupamento, que tem como finalidade reunir as unidades amostrais em grupos homogêneos (7), permitiu separar com base nos valores de taxa de progresso da doença, três grupos distintos de variedades de cebola quanto à resistência a doença. As variedades classificadas nos grupos 1, 2 e 3 foram consideradas suscetíveis, moderadamente suscetíveis e moderadamente resistentes à antracnose, respectivamente. Com exceção de Diamante, XP 3001 e XP 8010, as demais variedades mantiveram-se nos mesmos grupos nos dois anos de avaliação.

Embora todas as variedades testadas tenham sido suscetíveis à antracnose, com base nos sintomas foliares e enrodilhamento, houve uma clara distinção de três grupos, quanto à taxa de desenvolvimento da doença. Entre as variedades, aproximadamente a metade, isto é, as variedades Alfa Tropical, Alfa Tropical II, Belém IPA 9, Crioula Hortec, Crioula Roxa, Epagri 304, IPA 6, Régia, Rosada Empasc 358, Roxa IPA 3 e Super Precoce, apresentou as menores taxas de progresso. Isto sugere a existência de muitas fontes de resistência parcial. No entanto, deve-se ponderar que as condições prevalecentes de casa-devegetação, bem como a mistura de variedades, poderiam superestimar o nível de resistência das populações estudadas. Além disso, segundo Pedrosa et al. (9) não é seguro concluir se os componentes de resistência terão as mesmas tendências, sob condições de campo. Por isto, estudos epidemiológicos mais aprofundados precisam ser realizados a campo para verificar a eficiência das variedades com maior resistência parcial à antracnose-foliar, bem como, elucidar quais os componentes de resistência que atuam neles.

\section{REFERÊNCIAS BIBLIOGRÁFICAS}

1. Abreu, C.L.M. Reação de cultivares de cebola do ciclo de dias longos ao "mal-das-sete-voltas". Summa Phytopathologica, Jaboticabal, v.16, n.3/4, p.239-242, 1990.

2. Assunção, I.P.; Coelho, R.S.B.; Lima, G.S. de A.; Lima, J.A.S.; Tavares, S.C.C.de H. Reação de cultivares de cebola a isolados de Colletrotrichum gloeosporioides coletados na região do submédio São Francisco. Summa Phytopathologica, Jaboticabal, v.35, n.3, p.205-209, 1999.

3. Boff, P. Antracnose-foliar da cebola: diagnóstico e controle. Agropecuária Catarinense, Florianópolis, v.6, n.2 , p.34-37, 1993.

4. Galván, G.A.; Wietsma, W.A.; Putrasemedja, S.; Permadi, A.H.; Kik, C. Screening for resistance to anthracnose (Colletotrichum gloeosporioides Penz..) in Allium cepa and its wild relatives. Euphytica, Dordrecht, v.95, n.2, p.173-178, 1997.

5. Gandin, C.L.; Thomazelli, L.F.; Guimarães, D.R. Estádios de desenvolvimento da cebola. Agropecuária Catarinense, Florianópolis, v.15, n.1, p.53-56, 2002.

6. Gupta, R.P.; Srivastava, K.J.; Pandey, U.B. Diseases and insect pests of onion in India. Acta Horticulturae, Wageningen, v.358, p.265-269, 1994.

7. Liberato, J.R.; Cruz, C.D.; Vale, F.X.R.; Zambolim, L. Técnicas estatísticas de análise multivariada aplicada à fitopatologia. I. Análise de componentes principais, análise canônica e "cluster análise". Revisão Anual de Patologia de Plantas, Passo Fundo, v.3 p.227-281, 1995.

8. Melo, I.S.; Costa, C.P. Seleção massal em cebola (Allium cepa L.), população "Pira Ouro", para resistência a Colletotrichum gloeoporioides Penz. Sensu Arx, 1957. Summa Phytopathologica, Jaboticabal, v.9, n.3/4, p.214-219, 1983.

9. Pedrosa, R.A.; Maffia, L.A.; Mizubuti, E.S.G.; Brommonschenkel, S.H. Componentes de resistência em cebola a Colletotrichum gloeosporioides. Fitopatologia Brasileira, Brasília, v. 29, n.6, p.606-613, 2004.

10. Silva, N.; Costa, C.P. Reação de variedades e híbridos de cebola a Colletotrichum gloeosporioides, Penz. [sensu Arx, 1957]. Summa Phytopathologica, Jaboticabal, v.5, n.3/4, p.165-167, 1979. 